Research Article

\title{
DFT Study on the Reaction Mechanism of Cyclization of 2-Hydroxy Chalcone Catalyzed by Bronsted Acid with M06-2X Functional
}

\author{
Suci Zulaikha Hildayani1,*, Muhamad Abdulkadir Martoprawiro', Yana Maolana Syah² \\ ${ }^{1}$ Physical Chemistry Group, Department of Chemistry, Institut Teknologi Bandung, Bandung 40116, \\ Indonesia. \\ ${ }^{2}$ Organic Chemistry Group, Department of Chemistry, Institut Teknologi Bandung, Bandung 40116, \\ Indonesia.
}

Received: 20th June 2021; Revised: 21 th August 2021; Accepted: 22 ${ }^{\text {nd }}$ August 2021

Available online: 31st August 2021; Published regularly: December 2021

\section{Abstract}

Flavanones are one of the flavonoid group that has wide variety of applications such as a precursors in drug discovery. In the laboratory, flavanone is often synthesized from chalcone compounds. The conversion of chalcone to flavanone can be catalyzed by bronsted acid. The reaction mechanism for this process is proposed through the Michael addition reaction, however, the energetic details and the rate determining step for this reaction is not certainly known. This research aimed to investigate the reaction mechanism for chalcone-flavanone conversion with the present of bronsted acid as catalyst and also studied the effect of the solvent on the reaction energy profile with computational method. In this study, the modeling of the reaction mechanism for the said reaction was carried out using the DFT computational method with M06-2X functional. The computation was done both in the gas phase and in present of the solvent effect using the PCM models. The results showed that the mechanism of chalcone-flavanone conversion occurred in three steps which are protonation, cyclization, and then tautomerization. Based on these calculations, the rate determining step was the tautomerization reaction, which exhibited the same results with or without the solvent effects.

Copyright (C) 2021 by Authors, Published by BCREC Group. This is an open access article under the CC BY-SA License (https://creativecommons.org/licenses/by-sa/4.0).

Keywords: DFT; Reaction Mechanism; Chalcone Conversion; PCM Models; M06-2X

How to Cite: S.Z. Hildayani, M.A. Martoprawiro, Y.M. Syah (2021). DFT Study on the Reaction Mechanism of Cyclization of 2-Hydroxy Chalcone Catalyzed by Bronsted Acid with M06-2X Functional. Bulletin of Chemical Reaction Engineering \& Catalysis, 16(4), 796-803 (doi: 10.9767/bcrec.16.4.11487.796-803)

Permalink/DOI: https://doi.org/10.9767/bcrec.16.4.11487.796-803

\section{Introduction}

Flavonoids are secondary metabolites that are commonly found in plants. This group of compounds can be found in various plant tissues, including leaves, woods and barks, roots, seeds, fruit, and flowers. The important roles of flavonoids in plants includes being a UV light

* Corresponding Author.

Email: sz.hildayani@research.hki.or.id (S.Z. Hildayani);

Telp: +62-82137425245 filter, involved in the nitrogen fixation process, and as a compound responsible for flower coloring [1]. Apart from that, flavonoids also have various biological properties, including as antioxidant, anti-inflammatory, cancer prevention, reducing dementia risk, anti-asterclerosis, and diseases related to heart damage [2,3]. Thus, flavonoids are an important group of natural compounds that have studied by many researchers. Structurally, flavonoids have a carbon framework of C6-C3-C6. The basic structure of flavonoids include chalcone, flavanone, flavone, 
flavonol, dihydroflavonol, auron, leukoantocyanidin, proanthocyanidin and anthocyanidin $[4,5]$.

Flavanones are compounds in the flavonoid class known to have biological activities such as anti-cancer, anti-tumor, anti-bacterial, antimicrobial, antioxidant, esterogenic, and antiesterogenic. Flavanones are also known as precursor compounds for various other plant flavonoids, such as flavanols, dihydroflavanol, deoxyanthocyanidins, and various polyphenols. Based on the physiological properties related to physical attractiveness of the plants and also their promising role in the health sector for humans, various efforts have been made both to isolate flavanone compounds from plants and to carry out synthesis in the laboratory. In the laboratory, the synthesis of flavanones from the chalcone precursor with the formation of unsubstituted flavanone from 2'-hydroxychalcone could be occured with the help of catalysts such as mineral, ion-exchange resins, and acetic acids [5-7].

The reaction mechanism for the conversion of chalcone to flavanones in the presence of an acid catalyst is supposed to follow through the Michael addition reaction mechanism [8,9], but there is no past report regarding the energetics of the reaction mechanism or its rate determining step. By understanding a reaction mechanism, the reaction conditions could become easier to control and the resulting product could be optimized, both in yield and energy consumption. On the other hand, the development of computational chemistry could offer insight in understanding the nature of organic molecules for their structures, properties, and reactions [10]. Quantum mechanical computational method is one of the method that can be used in determining the mechanism of chemical reactions. Quantum mechanical calculations, especially with the density functional theory (DFT), are now applicable to real chemical systems studied by experimental chemists [11]. Based on those advantages of computational method, this work aimed to investigate the reaction mechanism of chalcone-flavanone conversion in the present of Bronsted acid using
DFT computational calculation with solvent effect study.

\section{Materials and Methods}

\subsection{Computational Details}

Quantum chemical calculations in this study were performed by using Gaussian 09 program package [12]. Softwares for molecular visualizations were carried out by software GaussView 5.0 [13], ChemCraft [14], and Jmol [15]. The geometry optimization for the reactants, intermediates, products and transition states was fully calculated with DFT method. The Density functional theory is based on the two Hohenberg-Kohn theorems stated that the ground-state properties of an atom or molecule are determined by its electron density function [16]. M06-2X [17] functional was employed. The energy cut-off was $10^{-5} \mathrm{~kJ}^{\mathrm{mol}}{ }^{-1}$ and the final RMS energy gradient was below 0.01 $\mathrm{kJ} . \mathrm{mol}^{-1} \cdot \mathrm{A}^{-1}$ [18]. For all calculations, the $6-311+(\mathrm{d}, \mathrm{p})$ basis set was used as the command $[19,20]$. The calculation of the solvent effect was carried out by using a continuous polarization model (PCM) [21] then was compared with the reaction model in the gas phase.

The results of the geometric optimization calculation for stable molecules had not showed any imaginary vibrations, while for the transition state had produced only one imaginary vibration with a frequency greater than 100 $\mathrm{cm}^{-1}$. Calculation of the Gibbs free energy of the reaction had been done by calculating the difference in energy relatively to the reactants.

\subsection{Proposed Reaction Mechanism}

The reaction mechanism, which was proposed in this study, is referred to Michael's intramolecular addition reaction mechanism [8] shown in Figure 1.

\section{Results and Discussion}

3.1. Optimization of geometry and calculation of transition state structures

Optimization of the molecular structure of the reactant (chalcone), two intermediates (I-1
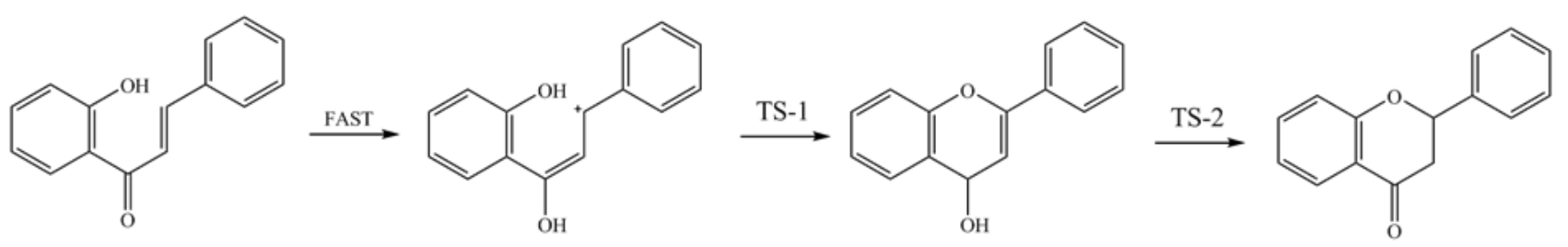

Figure 1. The reaction mechanism for the conversion of chalcone into flavanones followed Michael addition with methane sulfonic acid as catalyst. 
and I-2), and the product molecules (flavanone) had successfully carried out. The calculation results were showed in the Figure 2, each visualized molecules bellow had the lowest energy parameter.

The first step in the conversion reaction of chalcone to flavanone with a bronsted acid catalyst was the protonation of the carbonyl group by the $\mathrm{H}^{+}$ions from the catalyst formed a positively charged intermediate I-1. The positive charge in I-1 was redistributed until the most stable state was obtained. The change in charge around the protonation center was presented in Table 1. As expected from organic chemistry concept, the protonated carbonyl group had caused the positive charge at C3 increased.

The next step, the closing ring on the chalcone structure was occurred due to an attack from the $\mathrm{O} 17$ atom to the positively C3 and formed an oxygen-carbon bond in the intermediate I-2. The structure of the transition state

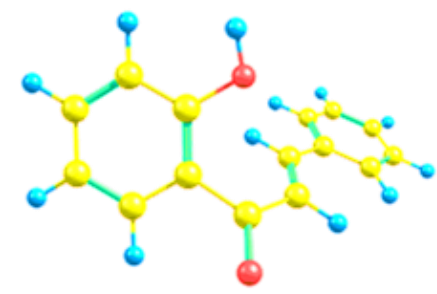

Reactant (Chalcone)

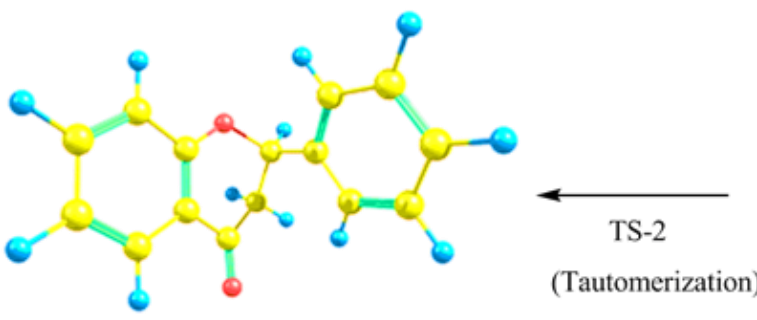

Product (Flavanone)
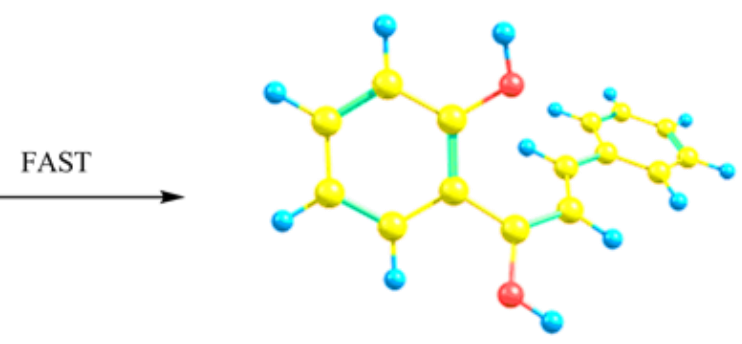

I-1 (Intermediate)
TS-1 (Cyclization Step)

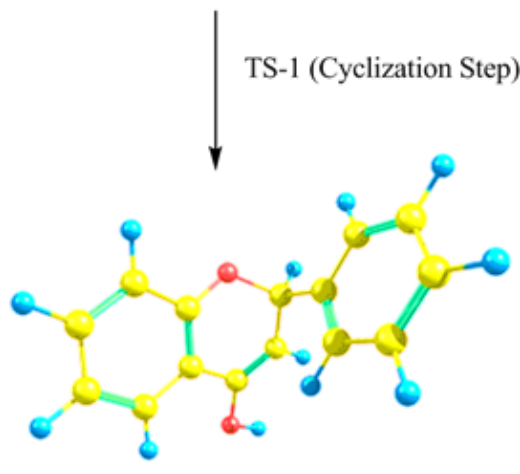

I-2 (Intermediate)

Figure 2. Visual stable structure of the reactants, intermediates, and calculated products.

Table 1. Charged atoms selected for the chalcone protonation stage.

\begin{tabular}{|c|c|c|}
\hline Atrm & $\mathrm{C}_{13}^{\mathrm{H}_{25}}$ & 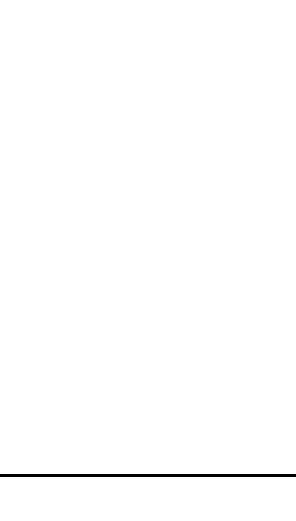 \\
\hline Atom & Before protonation & After protonation \\
\hline $\mathrm{O} 10$ & -0.234711 & -0.084022 \\
\hline $\mathrm{C} 1$ & -0.832241 & -0.656552 \\
\hline $\mathrm{C} 2$ & -0.583721 & -0.845075 \\
\hline $\mathrm{C} 3$ & +0.427900 & +0.535184 \\
\hline
\end{tabular}


(TS-1) of this step had successfully calculated and an imaginary vibration at the reaction center was obtained. Figure 3 showed the calculated TS-1 structure.

At tautomerization step, the hydroxyl functional group had changed to become a carbonyl. The H30 atom, which was originally bound to the $\mathrm{O} 10$ atom, had shifted to the $\mathrm{C} 2$ atom forming a new hydrogen-carbon bond between them. The removal of H30 atom had resulted the $\mathrm{O} 10$ atom to form a carbonyl structure. The structure of the transition state for the tautomerization step had calculated and shown in Figure 4.

\subsection{Reaction Gibbs Free Energy (Potential En- ergy Surface / PES)}

The calculation of the reaction Gibbs free energy had done by subtracting the correction factor for the sum of electronic energies with thermal free energies. In the Table 2 showed the relative Gibbs free energy values for each species in the conversion of chalcone to flavanone by comparing the reaction energy with and without solvent effect. While the profile of the reaction Gibbs free energy changes presented in Figure 5.

In the calculation results, both with or without a solvent effect, the activation energy for the tautomerization (TS-2) had relatively greater energy than the cyclization (TS-1), and had

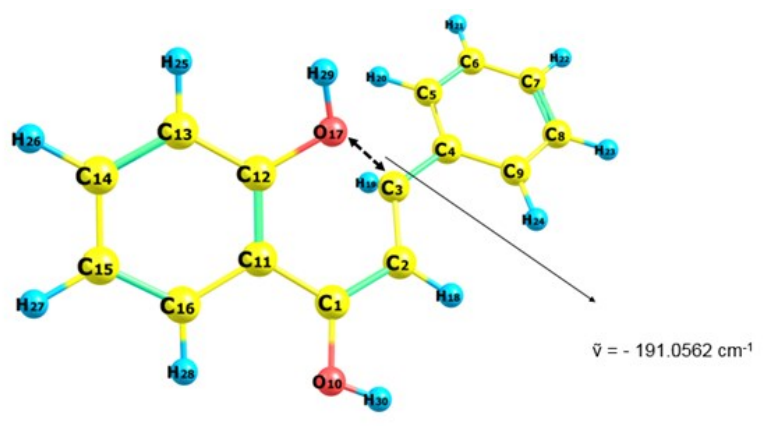

Figure 3. Visualization of the calculated TS-1 structure. concluded as the determining step for the reaction rate. However, it was clear that the solvent presence had affected the energy profile significantly, thus indicating the solvent had a big role in total reaction mechanism. So in order to produce more accurate data, it was necessary to add the solvent effect to the computational calculations.

From the PES graph, it can be seen that polar solvents, such as: ethanol and methanol, have a large stabilizing effect on the charged I2 and TS- 1 species, but not many on the neutral molecules. Meanwhile, non-polar solvents, such as toluene, provided less stabilization effect when compared to the gas phase.

In 2017, Gasque and co-workers published an article in Journal of Molecular Structure included computational calculations for the conversion of chalcone to flavanones with an alkaline catalyst and different type of reactant molecules [22]. From their calculation results, it was found that the rate determining step was the cyclization process, although the energy difference was relatively small. In contras, this study had used a Bronsted acid catalyst and the opposite results obtained, so that this study could provide a new picture in the conversion mechanism of chalcones to produce respective flavanones.

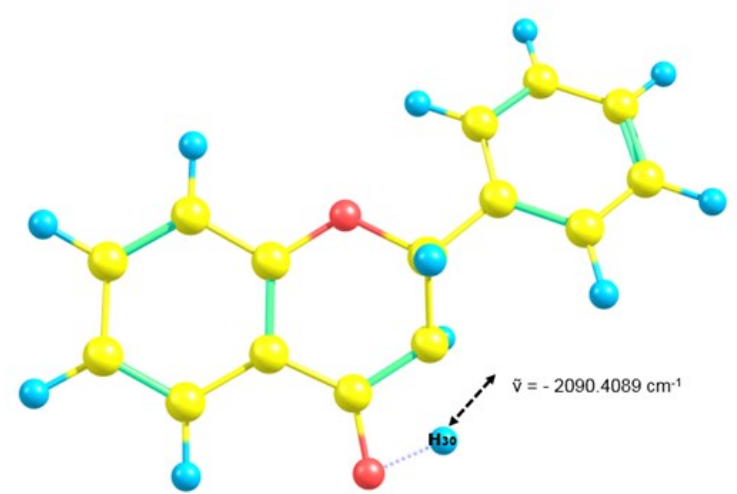

Figure 4. Visualization of the TS-2 structure calculated.

Table 2. Relative Gibbs free energy of each step in the reaction mechanism of chalcone conversion to flavanones in $\mathrm{kJ} / \mathrm{mol}$.

\begin{tabular}{lcccc}
\hline Stable Species & Gas Phase & in Ethanol & in Toluene & in Methanol \\
\hline Reactants & 0 & 0 & 0 & 0 \\
I-1 & 410.2898 & 53.00888 & 194.7545 & 49.57735 \\
TS-1 & 499.8562 & 136.4631 & 233.5935 & 132.9292 \\
I-2 & -12.8282 & -2.25793 & -7.66121 & -2.08465 \\
TS-2 & 223.9973 & 241.9216 & 232.4882 & 242.2314 \\
Product & -63.0934 & -50.3808 & -57.3803 & -50.1471 \\
\hline
\end{tabular}




\section{Conclusion}

The energy profile of the chalcone-flavanone conversion with the presence of an acid catalyst has been successfully determined by DFT computational method. The reaction mechanism occurred in three steps, which are protonation, cyclization, and tautomerization. Based on the activation energy, the tautomerization concluded as the rate determining step of the reaction. When including the solvent effect, the pattern of the potential energy obtained could partially change but the overall rate determining step showed the same results. Thus the polar solvent give higher stabilization effect than non polar solvent for the charged molecules when it compared to the reaction in the gas phase.

\section{Acknowledgment}

Authors would like to thank LPDP, Ministry of Finance Indonesia for funding this research with contract number 20160721028063 .

\section{References}

[1] Taylor, L.P., Grotewold, E. (2005). Flavonoids as Developmental Regulators. Current Opinion in Biology, 8, 317-323. DOI: 10.1016/j.pbi.2005.03.005.
[2] Cuyckens, F., Claeys, M. (2004). Mass Spectrometry in The Structural Analysis of Flavonoids. Journal of Mass Spectroscopy, 39, 1-15. DOI: 10.1002/jms.585.

[3] Jez, J.M., Noel, J.P. (2002). Reaction Mechanism of Chalcone Isomerase. The Journal of Biological Chemistry, 277, 1361-1369. DOI: 10.1074/jbc.M109224200

[4] Mondal, R., Gupta, A.D., Malik, A.K. (2011). Synthesis of Flavanones by Use of Anhydrous Potassium Carbonate as An Inexpensive, Safe, and Efficient Basic Catalyst. Tetrahedron Letters, 52, 5020-5024. DOI: 10.1016/j.tetlet.2011.07.072.

[5] Zang, Y., Wang, Y. (2014). Enantioselective Biomimetic Cyclization of 2' Hydroxychalcones to Flavanones. Tetrahedron Letters, 55, 3255-3258. DOI: 10.1016/j.tetlet.2014.04.032.

[6] Bhatti, H.A., Uddin, N., Ayub, K., Saima, B., Uroos, M., Iqbal, J., Anjum, S., Light, M.E., Hameed, A., Khan, K.M. (2015). Synthesis Characterization of Flavone, Isoflavone, and 2,3-Dihydrobenzeofuran-3-Carboxylate and Density Functional Studies. European Journal of Chemistry, 6(3), 305-313. DOI: 10.5155/eurjchem.6.3.305-313.1268
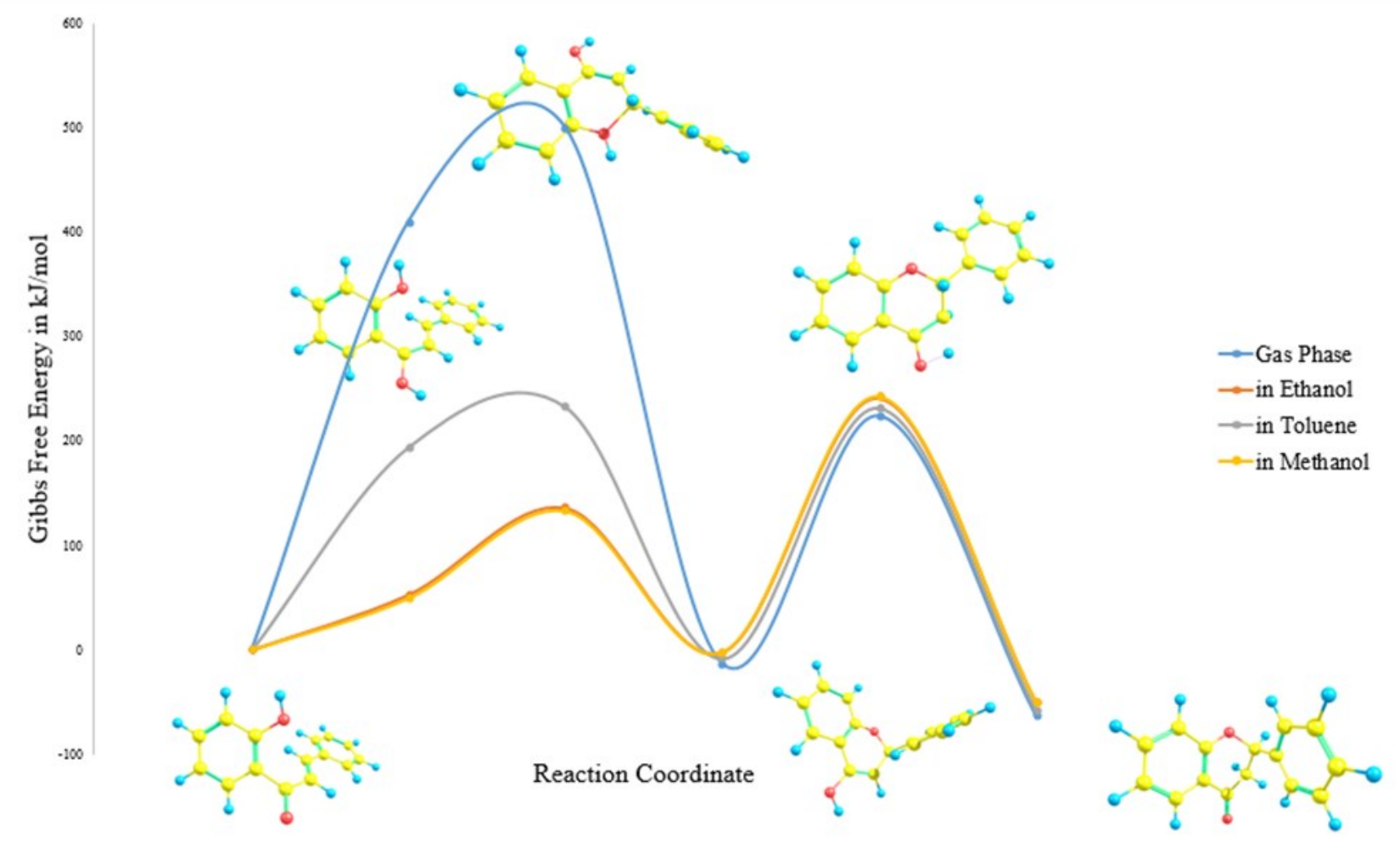

Figure 5. The potential energy surface (PES) graph of the conversion of chalcone to flavanones with an acid catalyst. 
[7] Albogami, A.S., Karama, U., Mousa, A.A., Khan, M., Al-Mazroa, S.A., Alkhathlan, A.Z. (2012). Simple and Efficient One Step Synthesis of Functionalized Flavanones and Chalcones. Oriental Journal of Chemistry, 28, 619626. ISSN: 0970-020 X

[8] Kulkarni, P., Wagh, P., Zubaidha., P. (2012). An Improved and Eco-Friendly Method for the Synthesis of Flavanone by the Cyclization of 2'-Hydroxy Chalcone using Methane Sulphonic Acid as Catalyst. Chemistry Journal, 2, 106-110. ISSN: 2049-954X.

[9] Dittmer, C., Raabe, G., Hintermann, L. (2007). Asymmetric Cyclization of 2'Hydroxychalcones to Flavanones: Catalysis by Chiral Bronsted Acids and Bases. European Journal of Organic Chemistry, 5886-5898. DOI: $10.1002 /$ ejoc.200700682

[10] Cramer, J.C. (2004). Essentials of Computational Chemistry, Theories and Models Second Edition. John Wiley \& Sons, Ltd

[11] Cheong, P.H., Legault, C.Y., Um, J.M., Celebi-Olcum, N., Houk, K.N. (2011). Quantum Mechanical Investigations of Organocatalysis: Mechanisms, Reactivities, and Selectivities. Chemical Review, 111, 5042-5137. DOI: $10.1021 / \mathrm{cr} 100212 \mathrm{~h}$.

[12] Gaussian 09, Revision D.01, Frisch, M.J., Trucks, G.W., Schlegel, H.B., Scuseria, G.E., Robb, M.A., Cheeseman, J.R., Scalmani, G., Barone, V., Mennucci, B., Petersson, G.A., Nakatsuji, H., Caricato, M., Li, X., Hratchian, H.P., Izmaylov, A.F., Bloino, J., Zheng, G., Sonnenberg, J.L., Hada, M., Ehara, M., Toyota, K., Fukuda, R., Hasegawa, J., Ishida, M. , Nakajima, T., Honda, Y., Kitao, O., Nakai, H., Vreven, T., Montgomery, J.A., Peralta, Jr., J. E., Ogliaro, F., Bearpark, M., Heyd, J.J., Brothers, E., Kudin, K.N., Staroverov, V.N., Keith, T., Kobayashi, R., Normand, J., Raghavachari, K., Rendell, A., Burant, J.C., Iyengar, S.S., Tomasi, J., Cossi, M., Rega, N., Millam, J.M., Klene, M., Knox, J.E., Cross, J.B., Bakken, V., Adamo, C., Jaramillo, J., Gomperts, R., Stratmann, R.E., Yazyev, O., Austin, A.J., Cammi, R., Pomelli, C., Ochterski, J.W., Martin, R.L., Morokuma, K., Zakrzewski, V.G., Voth, G.A., Salvador, P., Dannenberg, J.J., Dapprich, S., Daniels, A.D., Farkas, O., Foresman, J.B., Ortiz, J.V., Cioslowski, J., Fox, D.J., Gaussian, Inc., Wallingford CT, 2013.

[13] Nielsen, A.B., Holder, A.J. (2009). Gauss View 5.0, User's Reference. GAUSSIAN Inc., Pittsburgh.
[14] Chemcraft - graphical software for visualization of quantum chemistry computations. https://www.chemcraftprog.com

[15] Jmol: an open-source Java viewer for chemical structures in 3D. http://www.jmol.org/

[16] Lewars, E. G. (2011). Computational Chemistry : Introduction to the Theory and Applications of Molecular and Quantum Mechanics, 2nd Edition. Springer Science+Business Media

[17] Zhao, Y., Truhlar, D.G. (2008). The M06 Suite Of Density Functionals For Main Group Thermochemistry, Thermochemical Kinetics, Noncovalent Interactions, Excited States, And Transition Elements: Two New Functionals And Systematic Testing Of Four M06Class Functionals And 12 Other Functionals. Theoretical Chemistry Account, 120, 215-241. DOI: 10.1007/s00214-007-0310-x

[18] Cagardova, D., Michalik, M, Klein, E., Lukes, V., Marcovic, A. (2019). DFT And Ab Initio Calculations Of Ionization Potentials, Proton Affinities And Bond Dissociation Enthalpies Of Aromatic Compounds. Acta Chimica Slovaca, 12, 225-240. DOI: 10.2478/acs-20190032

[19] Wong, M.W., Gill, P.M.W., Nobes, R.H., Radom, L. (1988). 6-311G(MC) (d,p): A Second Row Analogue of the 6-31IG(d,p) Basis Set. Calculated Heats of Formation for SecondRow Hydrides. Journal of Physical Chemistry, 92, 4875-4880.

[20] Hariharan, P.C., Pople, J.A. (1973). The Influence of Polarization Functions on Molecular Orbital Hydrogenation Energies. Theoretical Chimica Acta, 28, 213-222

[21] Mennucci, B., Tomasi, J., Cammi, R., Cheeseman, J.R., Frisch, M.J., Devlin, F.J., Gabriel, S., Stephens, P.J. (2002). Polarizable Continuum Model (PCM) Calculations of Solvent Effects on Optical Rotations of Chiral Molecules. Journal of Physical Chemistry A, 106(25), 6102-6113. DOI: 10.1021/jp020124t.

[22] Gasque, L., Álvarez-Idaboy, J.R., FloresÁlamo, M., Guzmán-Méndez, Ó., CamposCerón, J.M. (2018). Theoretical and Experimental Study Demonstrates Kinetic Control in Chalconeflavanone Transformation of Naphthalene Derivatives. Journal of Molecular Structure, 1157, 631-637. DOI: 10.1016/j.molstruc.2017.12.078. 
Supplementary Data Part A. Optimized Geometry of Molecular Species Studied.<smiles>O=C(/C=C/c1ccccc1)c1ccccc1O</smiles>

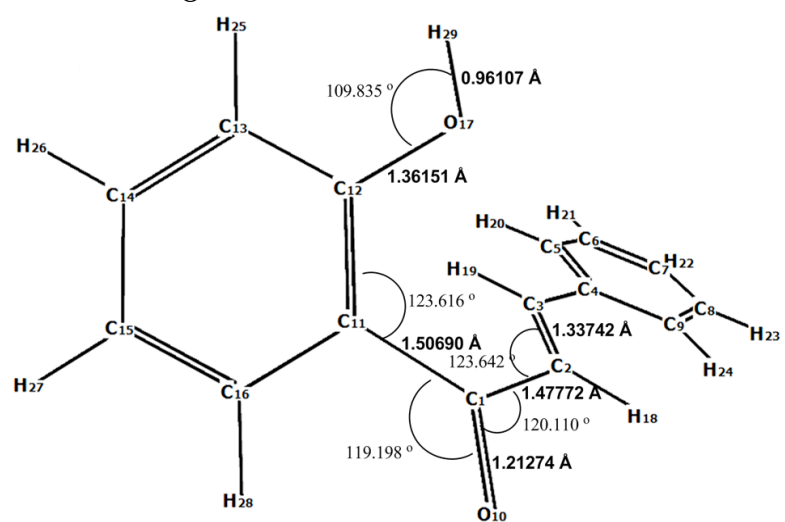

A1. Chalcone (M06-2X/6-311+G(d,p))<smiles>OC1C=C(c2ccccc2)Oc2ccccc21</smiles>

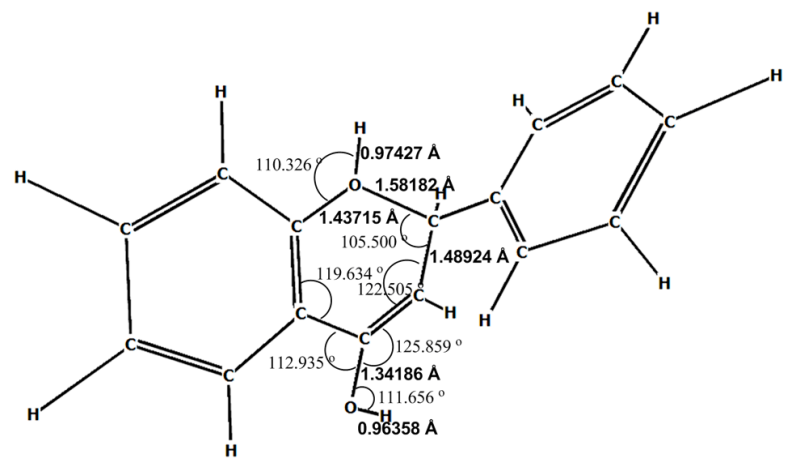

A3. Intermediate-2, cyclic cation (M06$2 \mathrm{X} / 6-311+\mathrm{G}(\mathrm{d}, \mathrm{p}))$<smiles>OC1=CC(c2ccccc2)C(O)=C2C=CC=CC12</smiles>

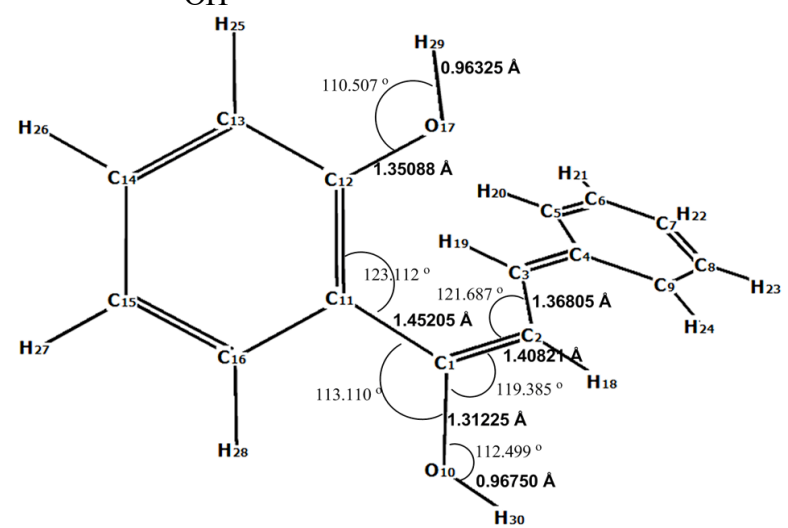

A2. Intermediate-1, carbocation (M06$2 \mathrm{X} / 6-311+G(d, p))$<smiles>OC1C=C(c2ccccc2)Oc2ccccc21</smiles>

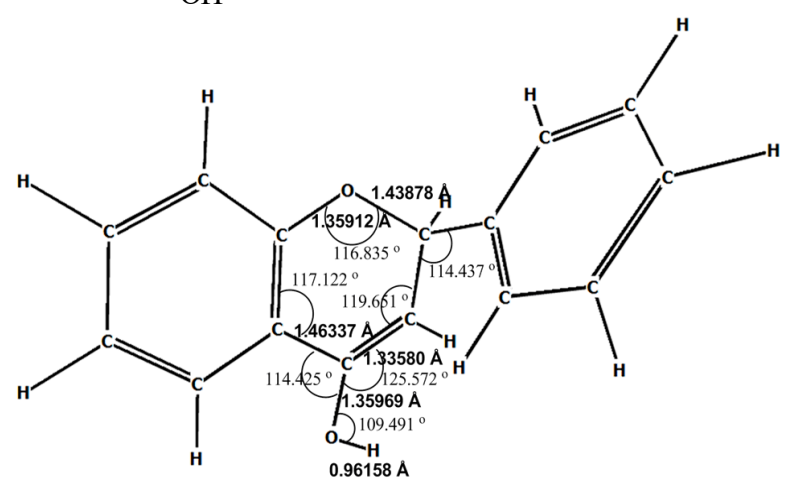

A4. Intermediate-3 (M06-2X/6-311+G(d,p)) 


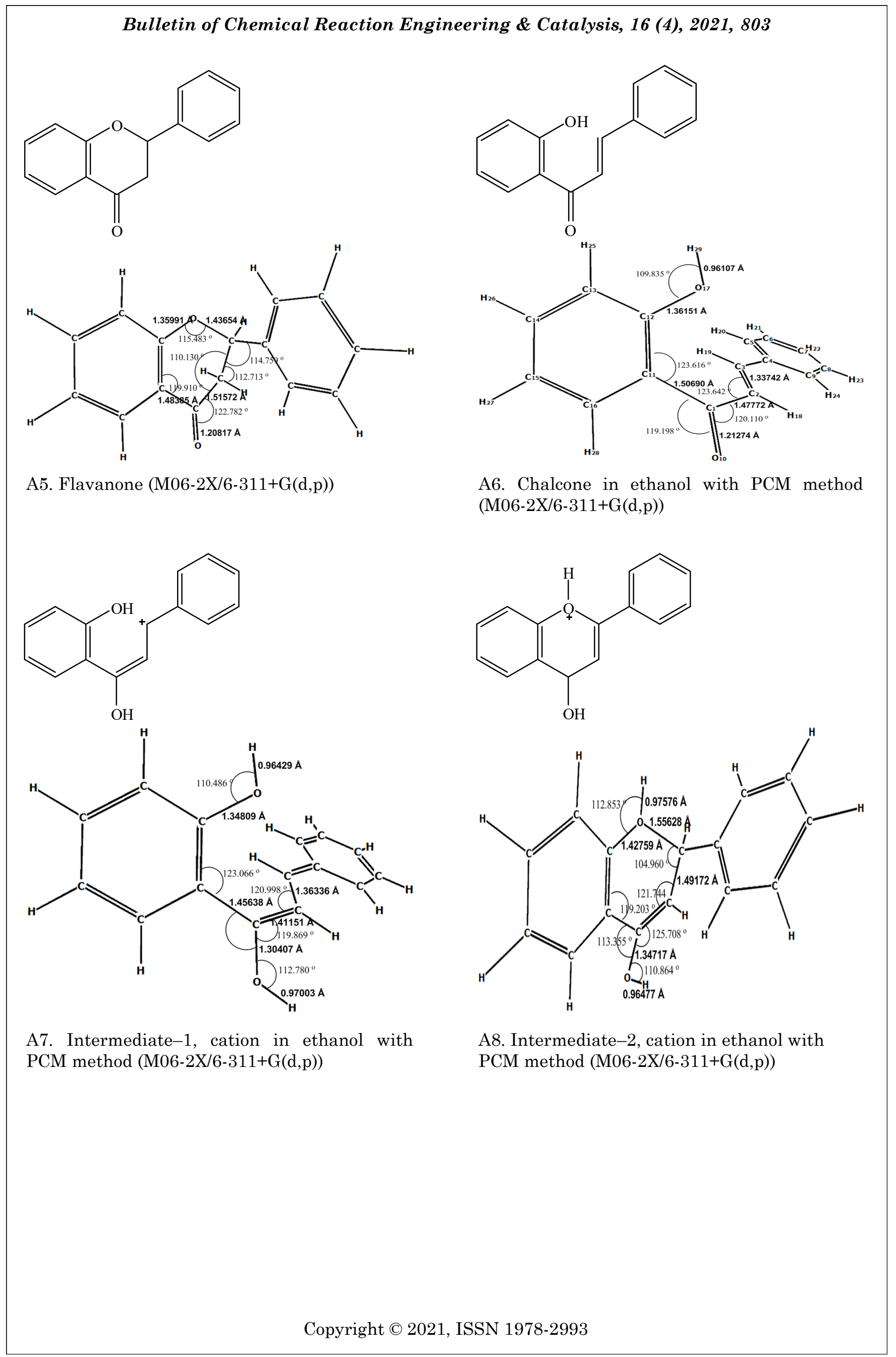

